\title{
EFFICACY OF CIPROFLOXACIN AND CEFOTAXIME IN PATIENTS WITH CIRRHOSIS LIVER PRESENTING WITH SPONTANEOUS BACTERIAL PERITONITIS TO A TERTIARY CARE HOSPITAL
}

\author{
Zahidullah Khan', Ahmar Rashid², Shams Suleman³, Iqbal Haider ${ }^{1}$, Aliena Badshah1, Inamullah Khan', \\ Wazir Mohammad Khan ${ }^{1}$, Jamal Ud Din ${ }^{1}$ \\ ${ }^{1}$ Department of Medicine, Khyber Teaching Hospital, Peshawar - Pakistan \\ ${ }^{2}$ Combined Millitary Hospital, Bahawalpur, Punjab - Pakistan \\ ${ }^{3}$ Department of Pharmacology, Khyber Girls Medical College, Peshawar - Pakistan
}

\begin{abstract}
Objectives: To compare the efficacy of Ciprofloxacin and Cefotaxime in Cirrhosis Liver patients with spontaneous bacterial peritonitis (SBP)

Materials and Methods: This prospective, comparative, single center study was conducted in the Department of Medicine, Khyber Teaching Hospital Peshawar from 1st October 2017 to 31st December 2018. A total of 300 admitted patients having Cirrhosis Liver with SBP were included in this study. The patients were randomized into Group A and Group B. Group A was treated with intravenous Ciprofloxacin and Group B was treated with intravenous Cefotaxime given twice daily for a period of 5 days. Diagnostic peritoneal paracentesis was done before the start of the treatment and repeated after 5 days therapy. Patients who were either non cirrhotic or had secondary bacterial peritonitis were excluded from the study.
\end{abstract}

Results: A total of 300 cirrhosis liver patients with SBP were studied in two equal randomized groups. Out of these 168 were male and 132 were female. The mean age of patients in study was $51.14 \pm 11.9$ years. The age ranged between $15-75$ years. In Group A, 82\% responded to ciprofloxacin and in group B, 86\% responded to cefotaxime.

Conclusion: Both intravenous ciprofloxacin and cefotaxime are effective in treating spontaneous bacterial peritonitis in patients with cirrhosis liver.

Key Words: Ciprofloxacin, Cefotaxime, Spontaneous bacterial peritonitis, Efficacy

This article may be cited as: Khan Z, Rashid A, Suleman S, Haider I, Badshah A, Khan I, Khan WM, Din JU. Efficacy of Ciprofloxacin and Cefotaxime in patients with Cirrhosis Liver presenting with spontaneous bacterial peritonitis to a tertiary care hospital. J Med Sci 2021 April;29(2):70-74

\section{INTRODUCTION}

Conn and Fessel defined spontaneous bacterial peritonitis (SBP) in 1971 as a syndrome manifested as infected ascitic fluid in patients with decompensated hepatic cirrhosis ${ }^{1}$. SBP is an infection of previously sterile ascitic fluid and the source of infection is not clearly identifiable but the infecting organisms usually belong to normal intestinal flora ${ }^{2,3}$. SBP can occur in both adults and children and is a well-recognized complication of cirrhosis of liver ${ }^{4}$.

The mechanism for bacterial inoculation of ascites

\section{Correspondence}

Dr. Iqbal Haider

Associate Professor

Department of Medicine, Khyber Teaching Hospital,

Peshawar - Pakistan

Email: driqbalhaiderkth@gmail.com

Cell: +92-313-9696102

Date received: $02-03-2021$

Date revised: $03-10-2021$

Date accepted: $05-24-2021$ has been a subject of great debate since Harold Conn ${ }^{1}$ who first described it, but evidence suggests that bacterial infection of ascitic fluid from intestine or hollow organ lumen occurs through transmural migration (bacterial translocation) and/or hematogenous route in combination with an impaired immune system ${ }^{1}$. The theory of bacterial translocation is supported by frequent isolation of enterotoxin from ascitic fluid ${ }^{5-8}$.

Bacterial infection of ascitic fluid is a common complication of decompensated cirrhosis. Its incidence is about $10-27 \%$ at the time of admission or after hospitalization ${ }^{9-11}$. Gram negative aerobic organisms are responsible in $75 \%$ of SBP cases, of which Klebsiella pneumonia organism accounts for $50 \%$ of these. Gram positive aerobic organisms are also responsible in minority, of which Streptococcus pneumoniae or Streptococcus Viridans group are the commonest ${ }^{12,13}$. As ascitic fluid is a high oxygen tension media so anaerobic bacteria are very rarely isolated in SBP. In most of cases only one infecting organism is isolated (92\%) though polymicrobial isolation has also 
Efficacy Of Ciprofloxacin And Cefotaxime In Patients With Cirrhosis Liver Presenting With Spontaneous Bacterial...

been reported ${ }^{14}$.

To establish the diagnosis of SBP ascitic fluid analysis obtained through paracentesis of peritoneal cavity is mandatory. In the microbial analysis total neutrophil count is the most valuable test to make the presumptive diagnosis of SBP. Usually a total neutrophil count in excess of 250 cells $/ \mathrm{mm}^{3}$ points towards a diagnosis of SBP and is considered valid evidence for the start of antibiotic treatment in symptomatic patients ${ }^{15}$.

As untreated, SBP can be fatal, starting empiric antibiotic therapy well in time improves the overall survival rates in patients. But despite timely treatment the mortality rate is about $10-30 \%$ and the survivors have a high chance of reinfection ${ }^{16,17}$.

Broad spectrum intravenous antibiotics having good coverage against gram negative aerobic organisms should be used as soon as SBP is diagnosed. SBP is usually treated with third generation cephalosporin but cefotaxime is the best choice which is given for 5 days. These drugs are highly efficacious and have no nephrotoxity and resolution is obtained in $80-90 \%$ of cases ${ }^{18,19}$.

Quinolones are used as alternative drugs in place of cephalosporins. The two mostly used quinolones are ciprofloxacin and ofloxacin. The pharmaceutical advantage for the prescribing physician is that both intravenous and oral preparations are available for both the categories of drugs. Studies have clearly shown that both quinolones and cefotaxime have comparable results and have no difference in resolution rate ${ }^{20,21}$.

The current study was aimed at comparing intravenous cefotaxime with intravenous ciprofloxacin in terms of resolution of infection and overall efficacy of treatment. This study would also help us understand the emergence of resistance against these two groups of antibiotics.

\section{MATERIAL AND METHODS}

This randomized non-blinded controlled trial was conducted in department of medicine, Khyber teaching hospital Peshawar (KTH) from 1st October 2017 to 31st December 2018. An Institutional ethical approval was granted for this research work through IREB of the institute. A total of 300 cases of decompensated cirrhosis liver with ascites who were admitted in the medical units in KTH were included in this study. Study population was 15 to 65 years old patients. Patients who had features of secondary peritonitis, those with ascites due to cardiac failure, renal failure or malnutrition, those currently using corticosteroids and a recent history of use of intravenous antibiotics in the last 7 days were excluded from the study, Additionally patients with normal ascitic fluid cytology or serum creatinine levels greater than $2 \mathrm{mg} \%$ or those patients who did not want to participate in trial were also excluded from the study.
A thorough history was taken and clinical examination of all patients was performed. All relevant laboratory investigations were performed in our local hospital laboratory under supervision of consultant pathologist. The diagnosis of SBP was established by ascitic fluid analysis before start of the study protocol. A total neutrophil count more than 250 cells $/ \mathrm{mm}^{3}$ in the setting of a transudative ascites with protein concentration less the 2.5 grams/ $\mathrm{dL}$ was considered as suggestive of SBP. Moreover, Ascitic fluid culture was done in those cases who had not received antibiotics in the last 3 days (before hospital admission). However, culture was not considered essential for the diagnosis. All patients were randoy divided into two groups by lottery method, group A and group B. Each group comprised 150 participants. Group A was assigned to receive $2 \mathrm{gm}$ intravenous cefotaxime twice a day and group B was assigned to receive $200 \mathrm{mg}$ intravenous ciprofloxacin twice a day. Both groups received antibiotic therapy for a total period of 5 days. After 5 days of therapy, ascitic fluid paracentesis was re-performed and a neutrophil count less than $250 / \mathrm{mm}^{3}$ along with absence of fever and abdominal pain was considered as a desirable outcomes.

All informations and demographic data like name, age, sex, address were recorded on pre designed proforma and analyzed using SPSS version 20. P value of $<0.05$ was considered significant. The results were presented in form of tables or graphs.

\section{RESULTS}

Total 300 patients were enrolled in the study, out of which 168 were male and 132 were female. The mean age of patients was $51.14 \pm 11.9$ years while age ranged between 15 and 75 years (Table 1 ).

The most common clinical presentations of patients were abdominal pain (77.7\%) followed by abdom-

Table 1: Age of patients (Years)

\begin{tabular}{|c|c|}
\hline Mean & 51.14 \\
\hline Std. Deviation & 11.95 \\
\hline Minimum & 15.00 \\
\hline Maximum & 75.00 \\
\hline
\end{tabular}

Table 2: Response to treatment

\begin{tabular}{|c|c|c|c|c|}
\hline \multicolumn{2}{|c|}{ Ciprofloxacin (Group A) } & Frequency & Percent & p-Value \\
\hline Response & Yes & 123 & 82.0 & \multirow{2}{*}{0.9} \\
\cline { 2 - 4 } & No & 27 & 18.0 & \\
\cline { 2 - 4 } & Total & 150 & 100.0 & \multirow{4}{*}{} \\
\hline \multirow{3}{*}{ Response } & Cefotaxime (Group B) \\
& Yes & 129 & 86.0 & \\
\cline { 2 - 4 } & No & 21 & 14.0 & \\
\cline { 2 - 4 } & Total & 150 & 100.0 & \\
\hline
\end{tabular}


Efficacy Of Ciprofloxacin And Cefotaxime In Patients With Cirrhosis Liver Presenting With Spontaneous Bacterial...

Table 3: Neutrophil count in Ascitic fluid

\begin{tabular}{|c|c|c|}
\hline Neutrophil Count (cells $/ \mathbf{~ m m}^{3}$ ) & Frequency & Percent \\
\hline $250-350$ & 49 & 16.3 \\
\hline $351-450$ & 56 & 18.7 \\
\hline $451-550$ & 65 & 21.7 \\
\hline $551-650$ & 56 & 18.7 \\
\hline $651-750$ & 37 & 12.3 \\
\hline$>751$ & 37 & 12.3 \\
\hline Total & 300 & 100.0 \\
\hline
\end{tabular}

Table 4: Age wise distribution of SBP

\begin{tabular}{|c|c|c|}
\hline Age Range (Years) & Frequency & Percent \\
\hline $15-25$ & 15 & 5.0 \\
\hline $26-35$ & 56 & 18.7 \\
\hline $36-45$ & 74 & 24.7 \\
\hline $46-55$ & 83 & 27.7 \\
\hline $56-65$ & 47 & 15.7 \\
\hline $66-75$ & 25 & 8.3 \\
\hline Total & 300 & 100.0 \\
\hline
\end{tabular}

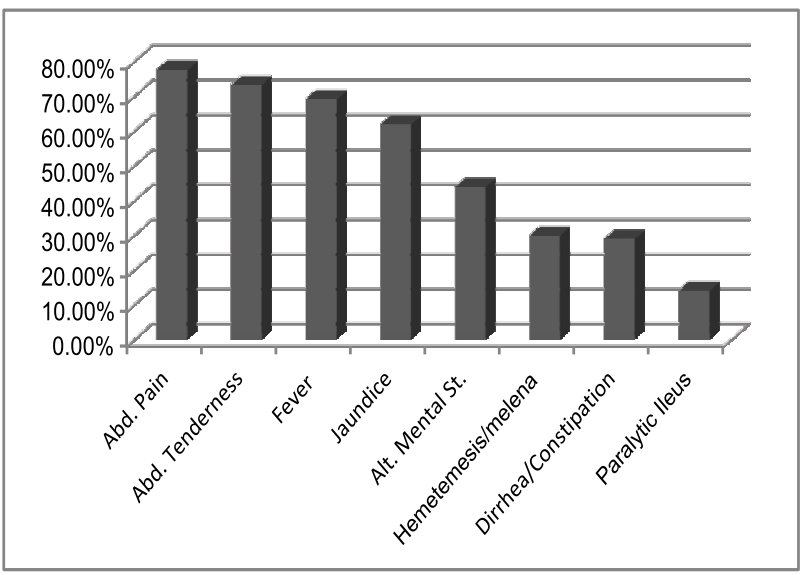

Fig 1: Clinical Presentation of SBP

inal tenderness (73.3\%) and fever (69.3\%) (Fig. 1).

Out of 150 patients with SBP in group A, 123 (82\%) patients responded to 5 days' infusion of Ciprofloxacin compared with 129 (86\%) patients who received 5 days infusion of Cefotaxime (P. value: 0.9).

Table 3 shows the results of ascitic fluid paracentesis. The results were further analyzed age wise and the age group found to be affected the most was $46-55$ years $(27.7 \%)$ followed by $36-45$ years (24.7\%) (Table 4$)$.

\section{DISCUSSION}

Spontaneous bacterial peritonitis (SBP) is an acute bacterial infection of ascitic fluid in the absence of any identifiable secondary bacterial infectious cause. Patients with decompensated cirrhosis are at higher risk of developing spontaneous bacterial peritonitis. It is a serious and a common complication of End Stage Liver Disease (ESLD). Clinically among patients who present with spontaneous bacterial peritonitis, $70 \%$ of them are in Child-Pugh class $\mathrm{C}^{22,23}$. Spontaneous bacterial peritonitis can occur in both children and adults. It can affect patients with cirrhosis due to any pathological cause and can occur as complication of Budd-Chiari syndrome.

We registered total of 300 patients in this study, dividing them into two equal groups randomly. The mean age of patients was 51 years in our study. Taskiran B reported mean age of 51 in a study comparing responses of Cefotaxime with Ofloxacin in SBP while Manohar TP reported mean age of 42 years which is less than our study 22- 24. In a local study conducted by Imran M, the mean age was 52 years which correlates with our study ${ }^{25}$. These results from above and many other sources demonstrate that SBP mostly develops in age group between 40 to 50 years denoting the commonest age of decompensation in most patients with Cirrhosis Liver.

Scores of local and international studies have deliberated on the prevalence of SBP in cirrhotic patients and response it shows to the different treatment regimens. This study compared the efficacy of two well-known drugs, Ciprofloxacin (Quinolone) and Cefotaxime (3rd Generation Cephalosporin). The aim was to know whether the efficacy of both drugs is the same or any different as in recent past a decline was noted due to the emergence of multiple drug resistance. In this study we compared the efficacy of both the given drugs in diagnosed cases of SBP and found that both the drugs were quite effective i.e. Ciprofloxacin vs. Cefotaxime ( $82 \%$ vs. $86 \%$ with p-Value 0.09$)$. Angeloni $\mathrm{S}$ also compared the efficacy of ciprofloxacin with cefotaxime however, his findings were that ciprofloxacin was more effective than cefotaxime in infection resolution $(80 \%$ vs. $41 \%)^{26}$. In another study, oral ciprofloxacin was proved to be slightly more effective than cefotaxime ( $80 \%$ vs $76 \%$ ) 27. Terg $\mathrm{R}$ and Tuncer I in their studies reported infection resolution rate of $78.4 \%$ and $80 \%$ with ciprofloxacin and cefotaxime respectively ${ }^{21-27}$. These studies nearly correlate with our study. In a local study conducted by Ahmad $\mathrm{M}$, quite high percentage of resistance was reported with sensitivity of $67 \%$ vs. $60 \%$ to ciprofloxacin and cefotaxime respectively ${ }^{28}$. A recent study conducted abroad by Yin $\mathrm{HJ}$ et al showed efficacy of $69 \%$ vs $76 \%$ to cefotaxime and ciprofloxacin respectively ${ }^{29}$. The results of this study are contradictory to our study. In a study conducted by Felisart $\mathrm{J}$ concluded that Cefotaxime was $85 \%$ effective in treatment of SBP ${ }^{30}$. A similar study was conducted on efficacy of cefotaxime by Runyon $B$ and it revealed that it cured $91 \%$ of SBP patients ${ }^{18}$. A recent local study conducted by Sarwar S reported $86 \%$ efficacy to Cefotaxime which correlate with our study ${ }^{31}$. All these results reveal that both ciprofloxacin and cefotaxime are still effective in the treatment of SBP and there is no significant difference in the efficacy of these two medications. 
Efficacy Of Ciprofloxacin And Cefotaxime In Patients With Cirrhosis Liver Presenting With Spontaneous Bacterial...

Regarding the clinical presentation of patients included in study, $77.7 \%$ had abdominal pain, $73.3 \%$ had abdominal tenderness, $69.3 \%$ had fever, $62 \%$ had jaundice, $44 \%$ had altered mental status, 30\% had hematemesis and melena, $29 \%$ had either diarrhea or constipation and $14.3 \%$ had paralytic ileus. Rashid A reported abdominal pain and tenderness in $78 \%$ of his population which is coinciding with our findings ${ }^{32}$. Different percentages of clinical signs and symptoms have been reported in other studies ${ }^{22,32-34}$. One study reported that $30 \%$ of patients with SBP were completely asymptomatic ${ }^{33}$. Another study conducted locally showed asymptomatic SBP in $7 \%$ of his studied population ${ }^{32}$.

Regarding age wise distribution, $27.7 \%$ of patients were in age range of $46-55,24.7 \%$ were in age range of $36-45$ and $18.7 \%$ were in age range of $26-35$. Nearly the same age wise distribution of patient has been reported by Ahmad $M$ and Aziz $A$ in their studies ${ }^{28,35,36 .}$

Regarding the neutrophil count in ascitic fluid, $21.7 \%$ patients had $451-550 / \mathrm{mm}^{3}$ and $18.7 \%$ had $351-450 /$ $\mathrm{mm}^{3}$ and $551-650 / \mathrm{mm}^{3}$. Only $12 \%$ had neutrophil count more than 750. Aziz A has reported mean neutrophil count of $283 \pm 305 / \mathrm{mm}^{3}$ while a local study reported quite high mean neutrophil count $\left(1760 / \mathrm{mm}^{3}\right)^{35,37}$.

Both the ciprofloxacin and cefotaxime need more clinical applications in the setting of SBP and can serve as a lifesaving tool aimed at improving the outcome of this serious disease especially in our set up where meager health facilities and resources are available.

Being a single centered study with limited number of patients are the pertinent limitations of this study. A large cohort randomized multicenter clinical trial is the need of time for generalization and validation of these outcomes.

\section{CONCLUSION}

Both ciprofloxacin and cefotaxime are still very effective in resolution of infection in spontaneous bacterial peritonitis and there is no significant difference in the efficacy of these two drugs. Both are quite cost effective as compared to drugs like Imipenem or Tazobactum.

\section{REFERENCES}

1. Conn HO, Fessel JM. Spontaneous bacterial peritonitis in cirrhosis: variations on a theme. Medicine 1971; 50:161-97.

2. Song DS. Spontaneous Bacterial Peritonitis. Korean J Gastroenterol. 2018;72(2):56-63

3. Soin S, Sher N, Saleem N. Spontaneous bacterial empyema: an elusive diagnosis in a patient with cirrhosis. Br Med J Case Rep 2018: http://dx.doi.org/10.1136/bcr2018-224810

4. Lata J, Stiburek O, Kopacova M. Spontaneous bacterial peritonitis: a severe complication of liver cirrhosis. World J Gastroenterol. 2009;15(44):5505-10.
5. Rimola A, Soto R, Bory F, Arroyo V, Piera C, Rodes J. Reticuloendothelial system phagocytic activity in cirrhosis and its relation to bacterial infections and prognosis. Hepatology 1984; 4:53-8.

6. Bolognesi M, Merkel C, Bianco S, Angeli P, Sacerdoti D, Amodio $P$, et al. Clinical significance of the evaluation of hepatic reticuloendothelial removal capacity in patients with cirrhosis. Hepatology. 1994; 19(3):628-34.

7. Garcia-Tsao G, Lee FY, Barden GE, Cartun R, West AB. Bacterial translocation to mesenteric lymph nodes is increased in cirrhotic rats with ascites. Gastroenterology 1995; 108:1835-41.

8. Maclntosh T. Emergency Management of Spontaneous Bacterial Peritonitis - A Clinical Review. Cureus. 2018;10(3):e2253.doi:10.7759/cureus.2253

9. Oey RC, de Man RA, Erler NS, Verbon A, van Buuren HR. Microbiology and antibiotic susceptibility patterns in spontaneous bacterial peritonitis: A study of two Dutch cohorts at a 10-year interval. United European Gastroenterol J. 2018;6(4):614-21.

10. Gines P, Arroyo V, Rodes J. Therapy of ascites and spontaneous bacterial peritonitis. In: Cohen S, Davis GL, Gianella RA (Editors). Therapy of Digestive Disorders: A Companion to Sleisenger and Fortran's Gastrointestinal and Liver Disease. Philadelphia: WB Saunders; 2000: 373-84.

11. Runyon A. Spontaneous bacterial peritonitis: An explosion of information. Hepatology. 1988;8:171-5.

12. Maraolo AE, Gentile I, Pinchera B, Nappa S, Borgia G. Current and emerging pharmacotherapy for the treatment of bacterial peritonitis. Expert Opin Pharmacother 2018;19(12):1317-25.

13. Oey RC, van Buuren HR, de Jong DM, Erler NS, de Man RA. Bacterascites: A study of clinical features, microbiological findings, and clinical significance. Liver Int 2018;38(12): 2199-2209.

14. Bolia R, Srivastava A, Marak R, Yachha SK, Poddar U. Prevalence and Impact of Bacterial Infections in Children With Liver Disease- A Prospective Study. J Clin Exp Hepatol 2018;8(1):35-41.

15. Rimola A, Soto R, Bory F. Reticuloendothelial system phagocytic activity in cirrhosis and its relation to bacterial infections and prognosis. Hepatology. 1984;4: 53-8.

16. Garcia-Tsao G. Spontaneous bacterial peritonitis. Gastroenterol Clin North Am 1992; 21:257-75.

17. Jamil S, Ahmed S, Memon A. Factors predicting the recurrence of spontaneous bacterial peritonitis in patients with cirrhosis. J Coll Physicians Surg Pak 2011;21:40710.

18. Runyon BA, McHutchison JG, Antillon MR, Akriviadis EA, Montano AA. Short-course versus long-course antibiotic treatment of spontaneous bacterial peritonitis. A randomized controlled study of 100 patients. Gastroenterology 1991;100:1737- 42.

19. Rimola A, Salmeron JM, Clemente G. Two different dosages of cefotaxime in the treatment of spontaneous bacterial peritonitis in cirrhosis: results of a prospective, randomized, multicenter study. Hepatology 1995; 21: 674-9. 
Efficacy Of Ciprofloxacin And Cefotaxime In Patients With Cirrhosis Liver Presenting With Spontaneous Bacterial...

20. Navasa M, Folio A, Llovet JM. Randomized, comparative study of oral ofloxacin versus intravenous cefotaxime in spontaneous bacterial peritonitis. Gastroenterology 1996; 111: 1011-7.

21. Terg R, Cobas S, Fassio E. Oral ciprofloxacin after a short course of intravenous ciprofloxacin in the treatment of spontaneous bacterial peritonitis: results of a multicenter, randomized study. J Hepatol 2000; 33: 564-9.

22. Manohar TP, Shejpal A. Spontaneous bacterial peritonitis in patients of cirrhosis of liver with ascites. Int $\mathrm{J}$ of Infec Dis 2016; 45:142-6.

23. Runyon BA. Management of adult patients with ascites due to cirrhosis: an update. Hepatology.2009;49(6): 2087-107

24. Taskiran B, Colakoglu O, Sozmen B, Unsal B, Aslan SL, Buyrac Z. Comparison of cefotaxime and ofloxacin in treatment of spontaneous bacterial peritonitis. Turkish $\mathrm{J}$ Gastroenterol 2004;15(1):34-8.

25. Imran M, Hashmi SN, Altaf A, Rashid H, Hussain T. Spontaneous Bacterial Peritonitis. Prof Med J 2006;13(2):2015

26. Angeloni S, Leboffe C, Parente A. Efficacy of current guidelines for the treatment of spontaneous bacterial peritonitis in the clinical practice. World $\mathrm{J}$ Gastroenterol 2008;14:2757-62.

27. Tuncer I, Topcu N, Durmus A, Turkdogan MK. Oral ciprofloxacin versus intravenous cefotaxime and ceftriaxone in the treatment of spontaneous bacterial peritonitis. Hepato gastro enterol 2003;50(53):1426-30.

28. Ahmad M, Mumtaz M, Mughal AA, Ali AA, Iqbal J. Spontaneous Bacterial Peritonitis. Prof Med J 2011;18(4):55761.

29. Yim HJ, Suh SJ, Jung YK, Kim MY, Baik SK, Kim HS, et al. Comparison of efficacy of cefotaxime, ceftriaxone, and ciprofloxacin for the treatment of spontaneous bacterial peritonitis in patients with liver cirrhosis: a randomized controlled trial. J of Hepatology 2017; 66(1):S374-5.

30. Felisart J, Rimola A, Arroyo V, Perez-Ayuso RM, Quintero $\mathrm{E}$, Gines P. Cefotaxime is more effective than is ampicillin-tobramycin in cirrhotics with severe infections. Hepatology 1985;5(3): 457-62.

31. Sarwar S, Tarique S, Waris U, Khan AA. Cephalosporin resistance in community acquired spontaneous bacterial peritonitis. Pak J of Med Sci 2019; 35(1):4-9.
32. Rasheed A, Qureshi ZA, Sarwar M. Spontaneous bacterial peritonitis in patients with cirrhosis and ascites. Professional Med J 2008;15(03):371-4.

33. Carey WD, Boayke A, Leatherman J. Spontaneous bacterial peritonitis: Clinical and laboratory features with reference to hospital-acquired cases. Am J Gastroenterol 1986;81:1156-61.

34. Bandy SM, Tuttle A. Spontaneous bacterial peritonitis. E-medicine from WebMD. Updated July 16, 2020.

35. Aziz A, Ashraf S, Talpur MT, Aamer N, Solangi SA, Shabir $\mathrm{KU}$, et al. Spontaneous Bacterial Peritonitis in Asymptomatic Cirrhotic Patients with Ascitis in a Tertiary Care Hospital: A Cross-Sectional Study. Pak Arm F Med J 2020;70(5):1408-12.

36. Ameer MA, Foris LA, Mandiga P, Haseeb M. Spontaneous Bacterial Peritonitis. In: StatPearls [Internet]. 2020 Jan.

37. Mehr MT, Khan H, Iman N. Frequency and types of spontaneous bacterial peritonitis in liver cirrhosis. J Med Sci $2011 ; 19(4): 200-3$

CONFLICT OF INTEREST: Authors declare no conflict of interest

GRANT SUPPORT AND FINANCIAL DISCLOSURE: NIL

\section{AUTHOR'S CONTRIBUTION}

Following authors have made substantial contributions to the manuscript as under

Khan Z: $\quad$ Concept and critical review.

Rashid A: Acquisition and proof reading.

Haider I: $\quad$ Analysis and interpretation of data.

Suleman S: Data collection and final approval.

Badshah A: Critical Rewiew.

Khan I: : $\quad$ Manuscript Writting.

Khan WM: Final drafting, manuscript evaluation.

Din JU:

Overall supervision, manuscript evaluation.

Authors agree to be accountable for all aspects of the work in ensuring that questions related to the accuracy or integrity of any part of the work are appropriately investigated and resolved. 